\section{BMJ Open Respiratory Research}

\title{
Pulmonary passport: a service evaluation study of a standardised web- based procedure logbook to aid specialist respiratory training and appraisal
}

\author{
Andrew Cheng, ${ }^{1}$ Tarek Saba, ${ }^{2}$ Tracy Duncan, ${ }^{3}$ Seamus Grundy, ${ }^{4}$ \\ Matthew Evison (D) ${ }^{1}$
}

To cite: Cheng A, Saba T, Duncan T, et al. Pulmonary passport: a service evaluation study of a standardised web-based procedure logbook to aid specialist respiratory training and appraisal. BMJ Open Resp Res 2020;7:e000690. doi:10.1136/ bmjresp-2020-000690

Received 24 June 2020 Revised 18 October 2020 Accepted 28 October 2020
Check for updates

(C) Author(s) (or their employer(s)) 2020. Re-use permitted under CC BY-NC. No commercial re-use. See rights and permissions. Published by BMJ

${ }^{1}$ North West Lung Centre, Wythenshawe Hospital, Manchester University NHS Foundation Trust, Manchester, UK

${ }^{2}$ Respiratory Medicine, Blackpool Teaching Hospitals NHS Foundation Trust, Blackpool, UK

${ }^{3}$ Respiratory Medicine, North Manchester General Hospital, Pennine Acute Hospitals NHS Trust, Manchester, UK

${ }^{4}$ Respiratory Medicine, Salford Royal Hospitals NHS Trust, Salford, UK

Correspondence to Dr Matthew Evison; m.evison@nhs.net

\section{ABSTRACT}

Introduction The pulmonary passport (PP) is a secure web-based procedural logbook for specialist respiratory trainees with enhanced functionality that includes automated analysis to provide key performance metrics and in-platform interactions with supervisors.

Methods This service evaluation study used preimplementation and postimplementation online surveys in both trainees and supervisors along with analysis of recorded data within the PP to evaluate the impact of this service on data capture, training, appraisal and quality assurance.

Results From August 2017 to August 2019, 69/73 (95\%) specialist respiratory trainees eligible to use the PP across two UK health education deaneries registered with the system and logged 7352 procedures. 3105 thoracic ultrasound procedures identified 2145 pleural effusions and resulted in 1253 pleural procedures of which $96 \%$ were successful. $4 \%$ of ultrasounds required referral to a more expert sonographer. latrogenic bleeding and pneumothorax both occurred in $\leq 1 \%$ of all pleural procedures. 1909 basic diagnostic bronchoscopies were recorded including 1236 bronchial washes, 328 brushes and 221 endobronchial biopsies where definite tumour was identified (biopsy sensitivity $74 \%$ ). Preimplementation and postimplementation survey data confirmed the PP had increased the consistency of logging procedures by trainees, the depth of data captured, the review of procedural performance metrics in appraisal and the frequency of formal supervisor feedback.

Discussion In this regional project, the implementation of a web-based procedural logbook has been feasible with excellent uptake and has enhanced procedural recording, supervision and appraisal. Furthermore, it provides unprecedented quality assurance at an individual trainee, trust and deanery level and has a number of potential wider applications in the future.

\section{INTRODUCTION}

The Joint Royal Colleges of Physicians Training Board (JRCPTB) respiratory curriculum mandates satisfactory recording of common

\section{Key messages}

What has been the impact of a novel, web-based procedural logbook (the pulmonary passport) on data capture, training, appraisal and quality assurance in specialist respiratory trainees?

- The pulmonary passport has increased the consistency of logging procedures, the depth of data captured, the review of performance metrics in appraisal and the frequency of supervisor feedback.

- This tool has the potential to drive standardisation of procedural monitoring, audit and performance review for both trainees and consultants within respiratory medicine and in other specialties.

respiratory procedures learnt by trainees such as bronchoscopy, thoracic ultrasound and pleural interventions. ${ }^{1}$ However, the official electronic training portfolio (National Health Service (NHS) ePortfolio) does not provide the ability to $\log$ all procedures performed by a trainee, instead educational supervisors and Annual Review of Competency Progression (ARCP) panels are reliant on the individual trainee producing a bespoke logbook or record of practice. This results in variable and inconsistent methods of logging procedures, ranging from maintaining electronic spreadsheets to handwritten notation. These methods are not standardised in format nor data collection and do not provide consistent measurement against established performance metrics. This, together with a lack of meaningful procedural data capture and the lack of quality assurance, made it challenging for supervisors to accurately assess procedural volume, experience and competency. Historically, limited exposure and poor-quality supervision in common respiratory procedures have contributed to trainee 
dissatisfaction. ${ }^{23}$ Furthermore, a trainee appraisal with an educational supervisor requires an assessment of procedural competency but potentially that supervisor might not perform the procedure in question themselves or may not have supervised the trainee performing the procedure directly. Without a robust record of procedural activity and performance, it is difficult for educational supervisors to undertake a robust evaluation of the trainee's progress and competency.

A review of published literature relating to bronchoscopy training depicts a clear need for a standardised, competency-based approach to procedural training ${ }^{45}$ and a move away from the historic focus on case numbers. ${ }^{6}$ There is currently both regional and international variation in the quality and availability of procedural training. ${ }^{78}$ Approaches to defining and achieving competency are described including the use of validated competency assessment tools, ${ }^{9-11}$ simulation training $^{12} 13$ and less formal 'supervisor sign-off. Within the UK, endoscopy training has been supported by an online procedural logbook as part of the Joint Advisory Group Endoscopy Training System. This has been associated with demonstrable improvements in quality of training and quality assurance of clinical endoscopy services. ${ }^{14}$ An electronic procedural logbook exists for surgical trainees in the UK and Ireland and is endorsed by national training boards. ${ }^{15}$ However, none existed for respiratory trainees.

The 'pulmonary passport' (PP) project was developed across two health education deaneries in the North West of England (North West and Merseyside Deaneries, 21 acute care trusts). The objective of this project was to provide a web-based application for specialist respiratory trainees that allows standardised recording of procedures, input of outcome data, performance analysis and 'in-platform' interaction with procedural supervisors. This platform would support high-quality procedural logging, supervision, competency confirmation and quality assurance which in turn may help to improve the overall standard and satisfaction with respiratory medicine training and enhance the appraisal process. In order to meet the project objectives, five critical functional components were identified for implementation within the PP; user interface, logging, performance analysis, training and appraisal. These were further divided into subfunctions (table 1) and embedded within an easy to navigate central dashboard in a secure platform (figure 1). Local charitable funds were secured to develop the PP website and the system was launched across the two deaneries in August 2017 and has been in operation ever since. The ongoing service costs are funded through a small cost that is top sliced from the trainee study budget at $£ 6$ per month per trainee.

The aim of this service evaluation study was to understand the mode and depth of procedural recording by specialist respiratory trainees in the two deaneries prior to the launch of the PP and then evaluate the impact of this service on data capture, training, appraisal and quality assurance following implementation. The results of this evaluation could then be used to understand the long term viability and sustainability of the service.

\section{METHODS}

\section{Baseline trainee data}

At any given time there are approximately 50-60 active specialist trainees within the Respiratory Medicine training programmes across the North West and Mersey Deaneries. In August 2020, following a regional call for volunteers to provide baseline information on procedural recording a cohort of 26 trainees were identified and sent a link to an online survey platform. Trainees were asked to provide information on which procedures they kept a logbook for and how they recorded their procedures prior to the PP (or if they were not currently using the PP). They were also asked which specific data fields they collected for selected procedures in which competence is required for completion of the training programme (basic diagnostic bronchoscopy, Seldinger chest drain insertion and thoracic ultrasound). These specific data fields mapped to the data fields collected within the standardised procedural logs in the PP to allow comparison on the depth of data collected between existing procedural logbooks and the PP system. Finally trainees were asked which procedural performance metrics they have previously been able to present within their appraisals prior to the PP (eg, sensitivity of endobronchial biopsies during basic diagnostic bronchoscopy when definite tumour seen). These metrics were also mapped to those routinely provided by the $\mathrm{PP}$ in order to compare the provision of these metrics preimplementation and postimplementation.

\section{Evaluating the impact of the PP: user and procedural data}

To evaluate the impact of the PP we evaluated uptake (number of trainees and supervisors registered with the website compared with number of trainees it is made available to, number of procedure logs completed and number of outcome logs completed), depth of procedural data captured (number and type of procedures, pathology identified, volume of diagnostic sampling), performance and quality assurance (immediate/late complication rates and diagnostic performance against recognised standards). Data analysis for the purpose of this report was performed on procedures completed between August 2017 and August 2019. In this manuscript, we have focused on the implementation and impact for specialist respiratory trainees and therefore focused on the basic respiratory procedures required for completion of specialist training such as thoracic ultrasound, pleural aspiration, Seldinger chest drain insertion and basic diagnostic bronchoscopy. 


\section{Table 1 Summary of the pulmonary passport functionality}

\begin{tabular}{ll}
\hline Component & Description \\
\hline User interface & User accounts-Separate accounts with appropriate functionality were designed for tran \\
& supervisors. Supervisor accounts allow feedback and assessment of competency and \\
& with named trainee accounts. \\
& Mobile access-A responsive user interface enables easy access on both desktop we \\
& mobile devices. All content and pages are flexible across all screen resolutions. As mob \\
& surpasses desktop usage, we prioritised removing any barriers to access by optimising \\
& Procedural logging-Individual standardised logging forms capture data for the follow \\
procedures: & Thoracic ultrasound \\
& Basic diagnostic bronchoscopy \\
& Endobronchial ultrasound bronchoscopy \\
& Chest drain insertion-Seldinger technique \\
& Dhest drain insertion-surgical technique \\
& Pleural fluid aspiration-diagnostic \\
& Pleural fluid aspiration-therapeutic \\
& Indwelling pleural catheter insertion \\
& Indwelling pleural catheter removal \\
& Local anaesthetic thoracoscopy \\
& Logs include demographic information, procedural data and immediate outcome data. \\
\end{tabular}

Outcome logging - Linked outcome logging allows for clinical data collection of procedural performance parameters such as biopsy results and late complications.

$\begin{array}{ll}\begin{array}{l}\text { Performance } \\ \text { analysis }\end{array} & \begin{array}{l}\text { Advanced reporting-Overall performance metrics can be displayed for each individual procedure. These } \\ \text { 'advanced reports' can be generated at a click of a button, displaying automatically calculated metrics such } \\ \text { as chest drain complication rate or sensitivity of endobronchial biopsies. They provide an immediate and } \\ \text { detailed summary of a trainee's procedural experience and competency for the purpose of monitoring and } \\ \text { appraisal. These reports also allow easy tracking of the learning curve to support high quality procedural } \\ \text { supervision. } \\ \text { Progress checker-A 'progress checker' allows a trainee to view the number of procedures they have } \\ \text { completed (both supervised and unsupervised) against recommended minimum numbers for each individual } \\ \text { procedure. }\end{array} \\ \text { Training } & \begin{array}{l}\text { Educational material-Educational booklets and training videos are hosted within the platform. This } \\ \text { material complements annual face-to-face procedural training courses and provides a readily accessible } \\ \text { reference point during all stages of specialist training. }\end{array} \\ \text { Appraisal } & \begin{array}{l}\text { Supervisor interaction-The in-platform link between trainee and supervisor accounts allows for easy and } \\ \text { efficient delivery of sign-off and formal feedback, with feedback forms produced for each procedure (free- } \\ \text { text written feedback). This supports a standardised and focused approach to procedural supervision. }\end{array} \\ & \begin{array}{l}\text { Competency sign off-Supervisors can generate competency sign-off certificates in Portable Document } \\ \text { Format (PDF) format. These can be uploaded to the NHS ePortfolio as further evidence of training } \\ \text { progression. }\end{array}\end{array}$

NHS, National Health Service.

\section{Evaluating the impact of the PP: survey data}

Within the same survey in August 2020, the same 26 trainees were asked to compare how consistently they recorded performing pulmonary procedures pre and post implementation of the PP using a five-point Likert scale for both time points (very consistently, consistently, somewhere in the middle, inconsistently, very inconsistently). They were also asked which specific functionality features of the passport they used (table 1). At the same time an additional cohort of 33 consultant chest physicians (also identified through a regional call for volunteers) were asked to complete an online survey that sought to evaluate the impact of the PP since implementation from a supervisor perspective. Consultants were asked how frequently they provided formal confirmation or written feedback of procedure supervision pre and post implementation of the PP also using a five-point Likert scale (very frequently, frequently, somewhere in the middle, infrequently, very infrequently) as well as which specific functionality features they used. Both trainees and supervisors were asked about future developments of the PP to enhance the user experience and effectiveness of the service.

\section{Data management/security}

All individual logs input to the PP are stored within encrypted PDF format and a secure web server (Microsoft 


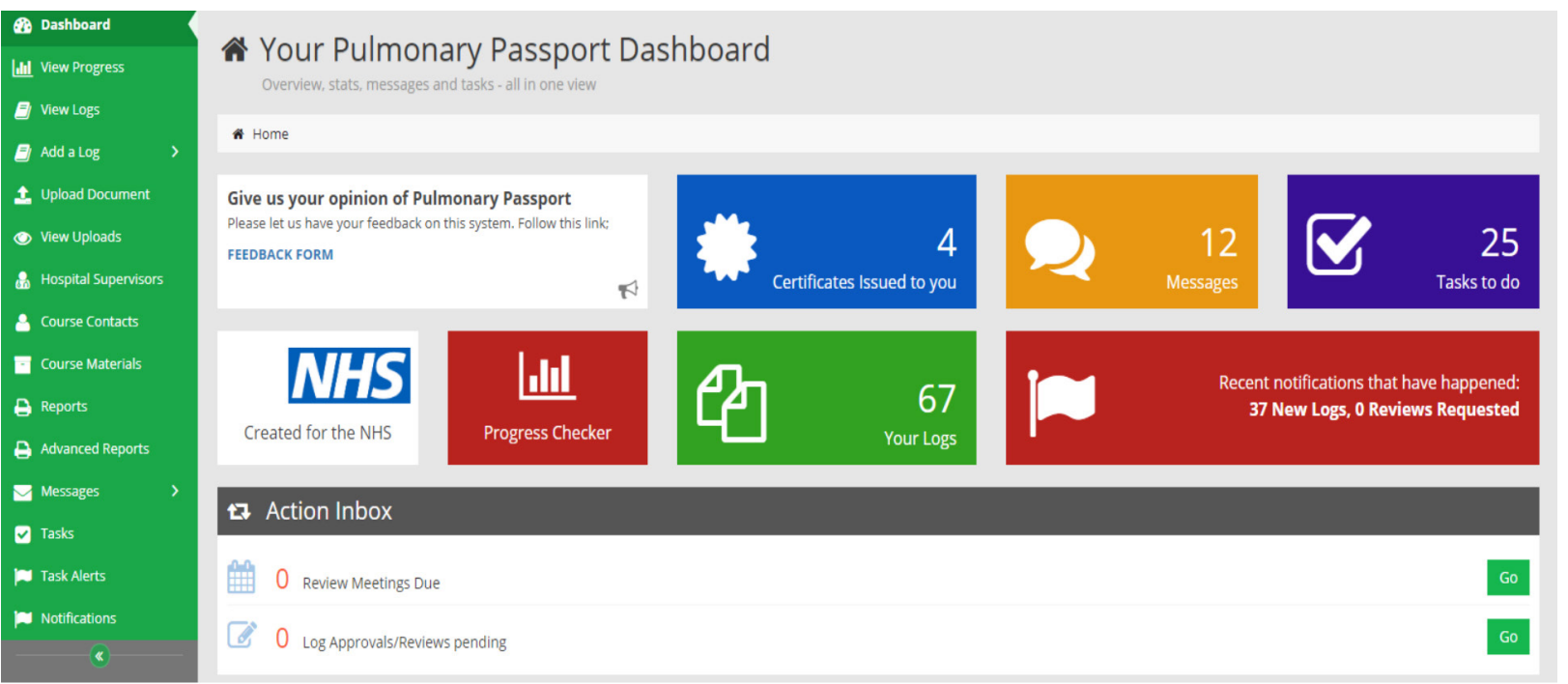

Figure 1 Screenshot of The pulmonary passport central dashboard.

Azure). No personal identifying data is recorded within the passport. Anonymised data can be analysed by a hospital or regional level but not at individual trainee's level. This dataset is only accessible to the project leads (ME and SG).

There was no specific Patient \& Public Involvement (PPI) required for this study centred on evaluating a medical education and training platform.

\section{RESULTS}

\section{Baseline trainee data}

All 26 trainees completed the pre-implementation online survey questions. There was broad representation across the 5 years of the training programme (year $1, \mathrm{n}=8$ $(30 \%)$, year $2, n=6(23 \%)$, year $3, n=5(19 \%)$, year $4, n=8$ $(30 \%)$, year $5, \mathrm{n}=3(12 \%)$ and one trainee was 'Out of Programme' undertaking research). The proportion of trainees who kept a procedure specific logbook prior to the PP were as follows: thoracic ultrasound 18/26 (69\%), diagnostic pleural aspiration $17 / 26(65 \%)$, therapeutic pleural aspiration $17 / 26(65 \%)$, Seldinger chest drain $18 / 26(69 \%)$, blunt dissection chest drain insertion $10 / 26(39 \%)$, indwelling pleural catheter insertion 15/26 (58\%), indwelling pleural catheter removal 5/26 (19\%), local anaesthetic thoracoscopy 11/26 (42\%), basic diagnostic bronchoscopy 16/26 (62\%) and endobronchial ultrasound (EBUS) 16/26 (62\%). Prior to the PP 20/26 $(77 \%)$ trainees used a bespoke database (eg, Microsoft excel), 2/26 (8\%) used paper records and 4/26 (15\%) did not keep any form of logbook. The proportion of trainees that recorded specific pre-defined data fields within their own logbooks in basic diagnostic bronchoscopy, Seldinger chest drain insertion and thoracic ultrasound are presented in figure 2. Prior to the PP 11/26 $(42 \%)$ of trainees captured the pathological results of sampling procedures during basic diagnostic bronchoscopy, $17 / 26(65 \%)$ and $7 / 26(27 \%)$ recorded immediate and late complications of Seldinger chest drain insertion, respectively, and 9/26 (35\%) recorded whether a referral to a more expert sonographer was required for thoracic ultrasound. The proportion of trainees who have been able to present specific performance metrics during their appraisal, prior to the PP, was: referral rate to a more expert sonographer for thoracic ultrasound $0 / 26(0 \%)$, uses of thoracic ultrasound to guide pleural effusion procedures $9 / 26(35 \%)$, success rate of ultrasound guided pleural procedures $8 / 26(31 \%)$, iatrogenic pneumothorax/haemothorax rate for pleural procedures 4/26 (15\%), chest drain displacement rate 2/26 $(8 \%)$, average number of biopsies taken at bronchoscopy when definite tumour seen $8 / 26(31 \%)$, sensitivity of endobronchial biopsies when definite tumour seen $9 / 26$ $(35 \%)$ and major complication rate for bronchoscopy $6 / 26(23 \%)$.

\section{PP uptake}

From August 2017 to August 2019, 69/73 (95\%) eligible respiratory specialist trainees from the North West and Mersey deaneries registered on the PP system. In the same time frame, 162 chest consultant supervisors registered with the PP. A total of 7352 procedures were logged in this time frame (an average of 107 procedures per trainee). The most common procedures were thoracic ultrasound $(n=3105)$, basic diagnostic bronchoscopy $(n=1909)$ and EBUS ( $n=728$, figure 3 ). Uptake of outcome logs was lower. For Seldinger chest drain insertion 48/521 (9\%) had an outcome log completed to document any late complications. There were 221 basic diagnostic bronchoscopies in which endobronchial biopsies in the presence of definite tumour were performed (12\% of all bronchoscopies). The histological results of these biopsies were completed within outcome logs in 63\% (139/221) of these cases. In the 1909 diagnostic bronchoscopies recorded in the passport system, $86 \%(1643 / 1909)$ were under either 

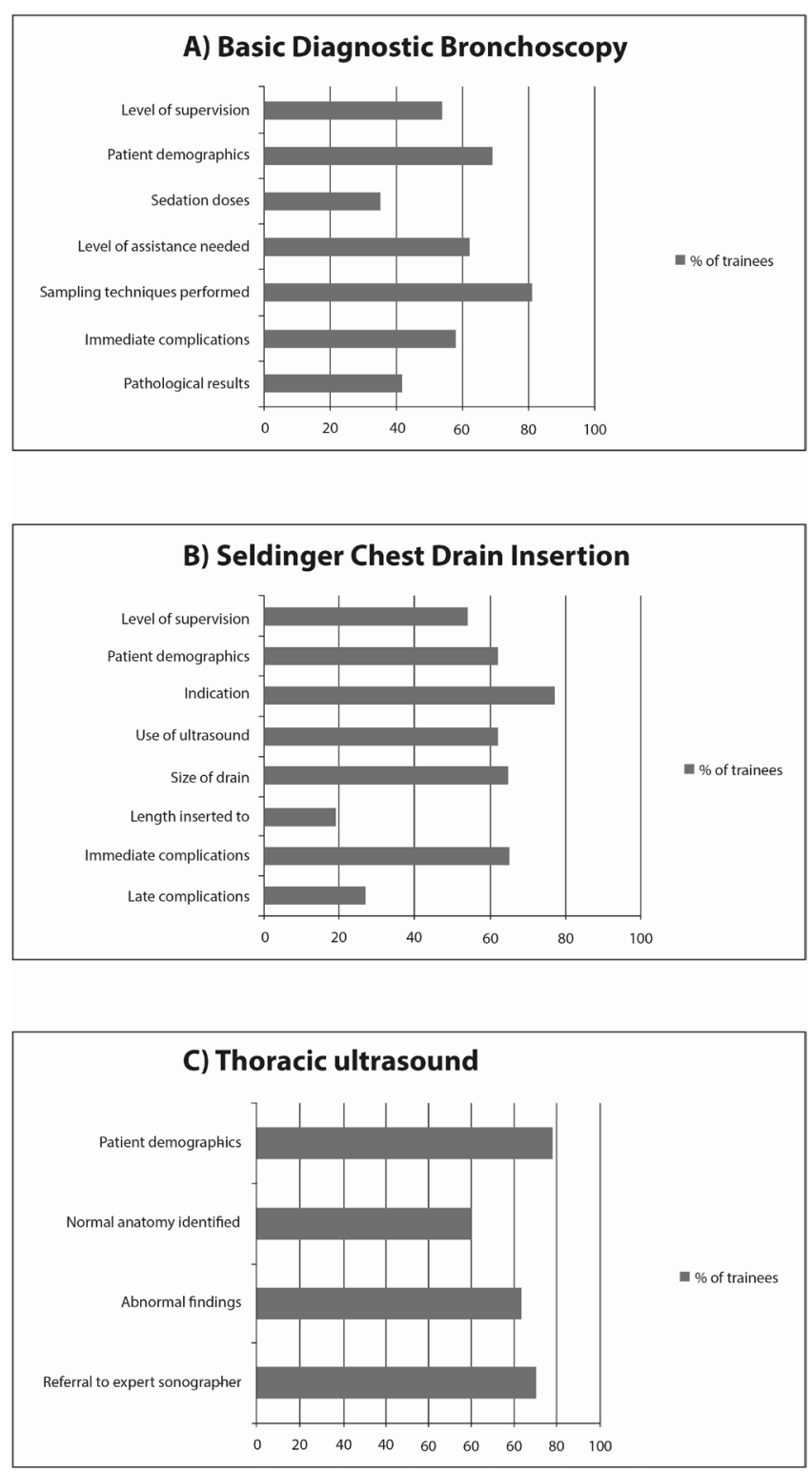

Figure 2 Proportion of trainees that record specific predefined data fields within procedural logbooks for (A) basic diagnostic bronchoscopy, (B) seldinger chest drain insertion, (C) thoracic ultrasound.

full (direct supervision of the entire procedure at the trainee's side, 26\%, 495/1909) or limited supervision (supervisor present in the room not necessarily at trainee's side, $61 \%, 1148 / 1909), 12 \%$ (225/1909) were under distant supervision (supervisor not present in the room but immediately available to attend if required) and $1 \%$ (19/1909) were unsupervised.

\section{Depth of procedural data captured}

A total of 3105 thoracic ultrasounds were recorded which identified 2145 pleural effusions (60\% of scans), 401 cases of consolidated lung ( $13 \%$ of scans) and 222 cases of pleural thickening (7\% of scans, table 2). A total of 1253 (40\% of scans) ultrasound scans were used to guide a subsequent (immediate) pleural procedure. A total of
521 chest drain insertions using the Seldinger technique were recorded. The drains were inserted for pleural effusions in 373 cases $(72 \%)$ and for a pneumothorax in 148 cases $(28 \%)$ with 10 cases (2\%) labelled as a hydropneumothorax. In the 1909 recorded basic diagnostic bronchoscopy procedures the most common diagnostic techniques used were bronchial wash $(\mathrm{n}=1236,65 \%)$, bronchial brush $(328,17 \%)$ and endobronchial biopsy in the presence of visible tumour $(\mathrm{n}=221,12 \%$, table 3$)$.

\section{Performance and quality assurance}

In thoracic ultrasound procedures $4 \%$ of scans (122/2891, table 1) were referred to more expert sonographer for interpretation and learning. In the 1253 thoracic ultrasounds that resulted in and guided a pleural procedure, 96\% (1205/1253) were successful procedures. The immediate complication rate for Seldinger chest drain insertion was $7 \%(36 / 521)$ with the most common immediate complication being failure of insertion at first pass $(4 \%, 21 / 521)$. Iatrogenic pneumothorax and iatrogenic bleeding both occurred in $<1 \%$ of cases (table 2 ). Only 48 'outcome logs' were recorded for Seldinger chest drain insertion. Of these, $10 \%(5 / 48)$ recorded the drain falling out prior to formal clinical decision to remove. No critical incidents were recorded as either an immediate or late complication. There were 495 diagnostic pleural aspirations recorded and 99\% (491/495) were performed using ultrasound guidance. The most common immediate complications were failure of the procedure $(4 \%, 21 / 495)$ and iatrogenic bleeding $(1 \%$, $5 / 495)$. No episodes of iatrogenic pneumothorax and no critical incidents were recorded. There were 443 therapeutic pleural fluid aspirations recorded and 98\% (435/443) were performed using ultrasound guidance. The most common immediate complications were failure of the procedure $(2 \%, 8 / 443)$, iatrogenic bleeding $(0.5 \%$, $3 / 435)$ and iatrogenic pneumothorax $(0.5 \%, 3 / 435)$. No critical incidents were recorded. In basic diagnostic bronchoscopy procedures, when definite endobronchial tumour was visually identified, the average number of biopsies taken was three. Five or more biopsies were taken in $33 \%$ of procedures. The sensitivity for providing tumour within endobronchial biopsies across all trainees was $74 \%$. Comparison between trusts revealed large variability in both the number of recorded biopsy outcomes and the sensitivity for tumour identification (figure 4). Transbronchial lung biopsy (TBLB) was performed in only $2 \%(35 / 1909)$ of procedures. Outcome data were complete in $100 \%$ of cases $(35 / 35)$ and revealed that lung parenchyma was present in 54\% (19/35) of biopsies. Only one trainee recorded their outcome for bronchoalveolar lavage so assessment of performance using the proportion of epithelial/other cells was not possible. The most common complications of basic diagnostic bronchoscopy were unexpected hospitalisation $(0.6 \%)$, severe bleeding $(0.3 \%)$ and death $(0.2 \%$, table 4$)$. 
Evaluating the impact of the PP: survey data

All 26 trainees completed the postimplementation online survey questions. Of 26, $23(89 \%)$ trainees used the PP for their procedural logbooks. The proportion of trainees that reported recording procedures 'very

\begin{tabular}{|c|c|c|}
\hline \multicolumn{3}{|l|}{ Thoracic ultrasound findings } \\
\hline Normal & 495 & $26 \%$ \\
\hline \multicolumn{3}{|l|}{ Abnormal } \\
\hline Pleural effusion & 2145 & $60 \%$ \\
\hline Pleural thickening & 222 & $7 \%$ \\
\hline Consolidated lung & 401 & $13 \%$ \\
\hline \multicolumn{3}{|c|}{$\begin{array}{l}\text { Referral to expert sonographer (2891 responses, } 214 \\
\text { unrecorded) }\end{array}$} \\
\hline Yes & 122 & $4 \%$ \\
\hline No & 2769 & $96 \%$ \\
\hline \multicolumn{3}{|c|}{ Effusion appearances (2011 responses, 1094 unrecorded) } \\
\hline Simple effusion & 1539 & $77 \%$ \\
\hline Complex effusion & 472 & $23 \%$ \\
\hline \multicolumn{3}{|c|}{ Pleural procedures (2166 responses, 939 unrecorded) } \\
\hline $\begin{array}{l}\text { No pleural procedure } \\
\text { performed }\end{array}$ & 913 & $42 \%$ \\
\hline $\begin{array}{l}\text { Successful pleural procedure } \\
\text { performed }\end{array}$ & 1205 & $56 \%$ \\
\hline $\begin{array}{l}\text { Unsuccessful pleural } \\
\text { procedure performed }\end{array}$ & 48 & $2 \%$ \\
\hline
\end{tabular}

consistently' increased from $31 \%$ to $50 \%$ following the implementation of the PP (figure 5). The proportion of trainees that use specific functions in the PP are as follows: mobile adjusted version $9 / 26(35 \%)$, procedural logs 23/26 (89\%), outcome forms 12/26 (46\%), progress checker 5/26 (19\%), advanced reports 13/26 $(50 \%)$, competency certificates $8 / 26(31 \%)$ and training resources $3 / 26(12 \%)$.

All 33 consultant chest physicians completed the online survey. Of 33, 24 (73\%) were registered supervisors on the PP. The proportion of consultants that reported the frequency with which they provided formal confirmation of procedure supervision or formal written feedback as 'very frequently' or 'frequently' increased from $21 \%$ to

Table 3 Immediate and late complication rates in respiratory trainees performing Seldinger chest drain insertion

Immediate complications (518 responses, 3 unrecorded)

\begin{tabular}{|c|c|c|}
\hline Failed insertion first pass & 21 & $4 \%$ \\
\hline latrogenic bleeding & 3 & $0.5 \%$ \\
\hline latrogenic pneumothorax & 5 & $1 \%$ \\
\hline Procedure abandoned & 7 & $1 \%$ \\
\hline Critical incident & 0 & $0 \%$ \\
\hline \multicolumn{3}{|c|}{ Late complications (48 responses, 472 unrecorded) } \\
\hline Pleural infection & 1 & $2 \%$ \\
\hline $\begin{array}{l}\text { Drain fell out prior to decision to } \\
\text { remove }\end{array}$ & 5 & $10 \%$ \\
\hline Critical Incident & 0 & $0 \%$ \\
\hline
\end{tabular}




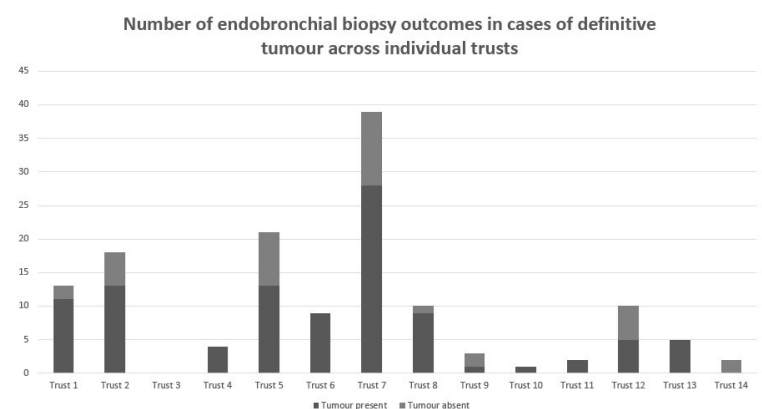

Figure 4 Number of endobronchial biopsy outcomes in cases of definitive tumour across individual trusts.

$33 \%$ pre and post implementation of the PP (figure 5). Of 33, $24(73 \%)$ consultants are educational supervisors and 11/24 (45\%) use the PP as part of their appraisal meetings. Of 24, $11(45 \%)$ if educational supervisors use the advanced reports and certificates to facilitate curriculum sign off and 7/24 (29\%) use the progress checker as part of the appraisal process.

Table 4 Supervision levels, sampling techniques and complication rates in respiratory trainees performing basic diagnostic bronchoscopy

\begin{tabular}{lrl}
\hline Supervision (1887 recorded, 22 unrecorded) & \\
\hline Full & 495 & $26 \%$ \\
\hline Limited & 1148 & $61 \%$ \\
\hline Distant & 225 & $12 \%$ \\
\hline Unsupervised & 19 & $1 \%$ \\
\hline Sampling techniques & & \\
\hline Bronchial wash & 1236 & $65 \%$ \\
\hline Bronchial brush & 328 & $17 \%$ \\
\hline Endobronchial biopsy (definite & 221 & $12 \%$ \\
\hline tumour) & & \\
\hline Endobronchial biopsy (other) & 158 & $8 \%$ \\
\hline Bronchoalveolar lavage & 173 & $9 \%$ \\
\hline Transbronchial lung biopsy & 17 & $1 \%$ \\
\hline $\begin{array}{l}\text { Conventional transbronchial needle } \\
\text { aspiration }\end{array}$ & 12 & $0.5 \%$ \\
\hline Complications & & \\
\hline Severe bleeding & 5 & $0.3 \%$ \\
\hline Cardiac arrhythmias & 2 & $0.1 \%$ \\
\hline Seizure & 2 & $0.1 \%$ \\
\hline Myocardial infarction & 0 & $0.0 \%$ \\
\hline $\begin{array}{l}\text { Pneumothorax requiring } \\
\text { intervention }\end{array}$ & 2 & $0.1 \%$ \\
\hline $\begin{array}{l}\text { Oversedation requiring reversal } \\
\text { Unexpected hospitalisation }\end{array}$ & 3 & $0.2 \%$ \\
\hline $\begin{array}{l}\text { Intensive Care Unit (ICU) admission } \\
\text { Death }\end{array}$ & 2 & $0.5 \%$ \\
\hline & 4 & $0.1 \%$ \\
\hline
\end{tabular}
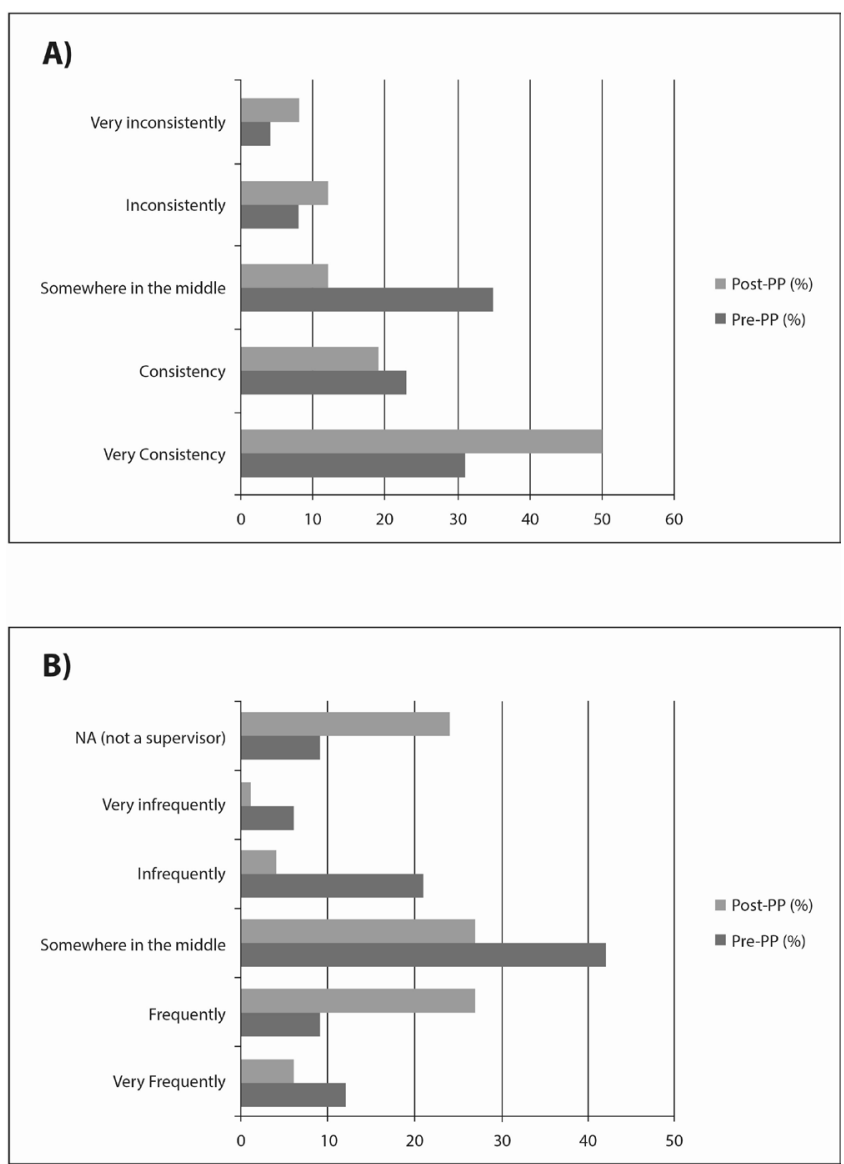

Figure 5 (A) Consistency of procedural logging and (B) frequency of providing confirmation of supervision or formal written feedback by consultant chest physicians preimplementation and postimplementation of the pulmonary passport (PP) using a five-point Likert scale.

\section{DISCUSSION}

\section{Key findings}

We report here the implementation of a novel web-based application which supports the standardised logging of respiratory procedures and summarises key clinical outcomes such as sensitivity of biopsy samples and rates of complications (an example of an advanced report produced by the PP is provided in figure 6). Prior to the PP we estimate, based on survey data, approximately two-thirds of trainees kept dedicated logbooks for basic respiratory procedures for which competency is required for completion of specialist training. This increased to $95 \%$ of trainees following implementation of the PP and the depth of data collection was immediately enhanced and standardised for all trainees via the use of this platform. For example, 93\% (2891/3105) thoracic ultrasound procedures recorded whether referral to a more expert sonographer was required whereas only an estimated $35 \%$ of trainees recorded this metric prior to the PP. One hundred pr cent $(521 / 521)$ of Seldinger chest drain procedures had immediate complications recorded in the PP whereas only an estimated $65 \%$ of trainees recorded this metric prior to the PP. Sixty-three per cent 


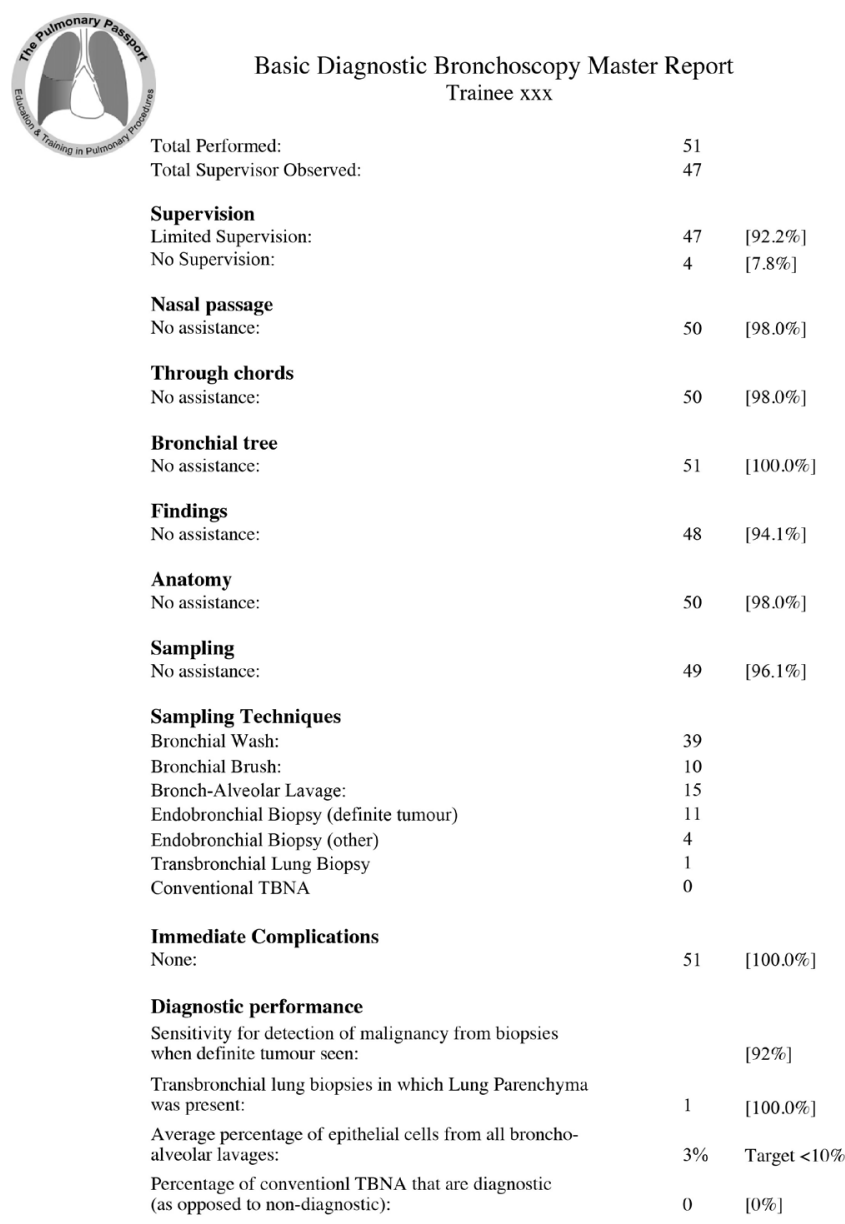

Figure 6 An example of an advanced report for bronchoscopy, summarising a trainee's log book and calculating key clinical outcomes. TNBA, transbronchial needle aspiration.

(139/221) of bronchoscopic biopsy procedures in cases of visible tumour had pathology results recorded in the PP whereas an estimated $42 \%$ of trainees recorded diagnostic outcomes from bronchoscopy prior to the PP. All trainees registered with the PP have access to advanced reports which analyse individual logbooks and present key performance metrics. Prior to the PP between $0 \%$ and $35 \%$ of trainees were able to report these performance metrics during an appraisal. Following the implementation of the PP $95 \%$ of trainees have access to this function, an estimated $50 \%$ of trainees use this functionality regularly and an estimated $50 \%$ of supervisors use these reports within appraisals. Preimplementation and postimplementation surveys confirm increased consistency of recording procedures and increased frequency of feedback from supervisors. It is reasonable to conclude from this evaluation study, therefore, that the PP has improved the process of procedural logging, supervision and appraisal. Beyond the benefits to individual trainees the data submitted to the PP can effectively support the quality assurance of procedural training at a hospital and deanery level. It allows inspection of the training
Table 5 Proposals for quality standards in procedural training in respiratory medicine

\begin{tabular}{|c|c|}
\hline Procedure & Quality standard \\
\hline Thoracic ultrasound & $\begin{array}{l}\text { Referral to more expert sonographer } \\
<5 \%\end{array}$ \\
\hline Thoracic ultrasound & $\begin{array}{l}\text { Success rate of ultrasound guided } \\
\text { pleural procedures }>95 \%\end{array}$ \\
\hline Pleural aspiration & $\begin{array}{l}\text { latrogenic pneumothorax/ } \\
\text { haemothorax rate }<1 \%\end{array}$ \\
\hline Pleural aspiration & Use of ultrasound guidance $>95 \%$ \\
\hline $\begin{array}{l}\text { Seldinger chest drain } \\
\text { (pleural effusion) }\end{array}$ & Use of ultrasound guidance $>95 \%$ \\
\hline Seldinger chest drain & $\begin{array}{l}\text { latrogenic pneumothorax/ } \\
\text { haemothorax rate }<1 \%\end{array}$ \\
\hline Seldinger chest drain & $\begin{array}{l}\text { Drain fall out rate (prior to clinical } \\
\text { decision to remove) }<10 \%\end{array}$ \\
\hline $\begin{array}{l}\text { Basic diagnostic } \\
\text { bronchoscopy }\end{array}$ & $\begin{array}{l}\text { No of biopsies when definite tumour } \\
\text { seen } \geq 5^{\star}\end{array}$ \\
\hline $\begin{array}{l}\text { Basic diagnostic } \\
\text { bronchoscopy }\end{array}$ & $\begin{array}{l}\text { Sensitivity of biopsies when definite } \\
\text { tumour seen }>85 \%^{*}\end{array}$ \\
\hline $\begin{array}{l}\text { Basic diagnostic } \\
\text { bronchoscopy }\end{array}$ & Major complication rate $<1 \%$ \\
\hline
\end{tabular}

${ }^{*}$ Existing national quality standard.

opportunities at individual trusts, outcome measures stratified by individual trusts and across the region. This can also highlight areas of good practice and quality attainment but also highlight areas warranting further exploration if any concerns are raised. For example, rates of TBLB $(0.9 \%)$ and conventional transbronchial needle aspiration (cTBNA, 0.6\%) are extremely low. This supports a recent national survey which found that a significant proportion of senior trainees did not feel competent in TBLB. ${ }^{3}$ Additionally, our outcome recordings showed that in TBLB, lung parenchyma was only present in 56\%, indicating poor quality. These results question whether it is appropriate to include TBLB, cTBNA within the core skills and competency framework of a general bronchoscopist in training. The combined data from across the deaneries also helps to define appropriate performance standards based on large scale reallife outcomes across the trainees. These can be combined with existing national standards to produce a portfolio of performance metrics that could act as a framework for appraisal of a trainee's logbook. A proposal for such a framework is provided in table 5 .

\section{Future applications}

This web-based system has a number of potential wider applications. The British Thoracic Society (BTS) has recently produced a Thoracic Ultrasound Training Standard. ${ }^{16}$ This new training pathway aims to create a new pool of thoracic ultrasound operators that can provide thoracic ultrasound in an emergency scenario, for example, out of hours large pleural effusion requiring 
intervention. This training pathway may be relevant to a broad range of healthcare and specialties that might provide out of hours thoracic ultrasound, for example, acute medicine, general internal medicine, critical care and critical care outreach teams. The training pathway is structured using 'capabilities in practice' (CiP), a graded approach to the confirmation of competency. ${ }^{17}$ An electronic logbook, such as the PP, could facilitate the monitoring and progress of trainees through a thoracic ultrasound CiP. Pleural specialist nurses are an increasingly important part of pleural services but require dedicated pleural training. However, a standardised training framework for pleural specialist nurses does not exist. The BTS training standard for thoracic ultrasound may help address some of this but not for all aspects of pleural training. The PP could facilitate robust and systematic recording of pleural procedures within a training programme for specialist nurses and allow the same quality assurance it affords to respiratory trainees. Finally, the PP could be expanded to include a greater breath of procedures both medical and surgical. The basic template of electronic logging and performance monitoring has been proven to be feasible and acceptable. The addition of further procedures ranging from basic medical procedures in medical school and junior doctor training (eg, venepuncture, cannulation) through to more advanced medical procedures (central line insertion, ascitic drains, lumbar punctures) and complex surgical procedures could all be added to the passport system and provide the same benefits to its users.

\section{Limitations}

While the completion of procedural logs has been excellent, the uptake of enhanced functionality has been lower than desired. It is within these enhanced functions (outcome logs, certification, advanced reports) that the true value of the system is to be gained, particularly in the process of appraisal and ARCP panels. These functions represent a potential vehicle to the standardisation of procedural assessment during appraisals and a focus for this project in the future must be to increase the uptake of this functionality. One potential method to achieve this would be to increase the supervisor engagement in the PP and one mechanism for this could be the ability of consultants to log their own procedures in the PP, with the benefits of advanced reports for the purpose of their own appraisal. This was requested frequently by supervisors completing the postimplementation survey in the free-text section for suggested improvements to the PP. While the implementation of a new method for logging respiratory procedures has been proven feasible within two adjacent deaneries this does not confirm widespread adoption would occur at a wider scale. Large-scale implementation would require a clearly defined funding model that would secure ongoing technology support, hosting costs, enhancements and long-term sustainability.

\section{CONCLUSIONS}

The PP is a novel solution to standardise logging of respiratory procedures and supports procedural supervision and training. It synergises well with the JRCPTB NHS ePortfolio which is designed primarily for the purposes of competency assessment rather than logging. This tool has the potential to drive standardisation of procedural monitoring, audit and performance review for both trainees and consultants within respiratory medicine and in other specialties. National adoption, development and expansion could be explored.

Acknowledgements The funding to develop the Pulmonary Passport was provided by the North West Lung Centre Charity, based at Wythenshawe Hospital, Manchester University NHS Foundation Trust. The clinical team partnered with One Vision Health, a health education agency, to design the web-based system and the functionality (with particular thanks to Dave Amos and Sam Bevan). Additional funding for further enhancements to the system, specifically centred on advanced reporting, was provided by Rocket Medical. One Vision Health continue to host the website and provide technology support to users. The project has been supported by Training Programme Directors Catherine Houghton, Mark Wilkinson, Vinay Shanker and Paul Stockton. Many clinicians in the North West region have contributed to the development of this project through their contributions to the North West Pleural Network.

Contributors AC, SG and ME were responsible for survey design, survey dissemination, data analysis and manuscript writing. TD and TS provided further review of the manuscript. All authors approved the final version.

Funding This work was funded by an initial grant from the North West Lung Centre Charity and further upgrades work funded by an unrestricted educational grant from Rocket Medical UK.

Competing interests None declared.

Patient and public involvement Patients and/or the public were not involved in the design, or conduct, or reporting, or dissemination plans of this research.

Patient consent for publication Not required.

Ethics approval This is a service evaluation study and did not require formal ethical approval, agreed with the lead local research and development team.

Provenance and peer review Not commissioned; externally peer reviewed. Data availability statement No data are available. Not applicable.

Open access This is an open access article distributed in accordance with the Creative Commons Attribution Non Commercial (CC BY-NC 4.0) license, which permits others to distribute, remix, adapt, build upon this work non-commercially, and license their derivative works on different terms, provided the original work is properly cited, appropriate credit is given, any changes made indicated, and the use is non-commercial. See: http://creativecommons.org/licenses/by-nc/4.0/.

ORCID iD

Matthew Evison http://orcid.org/0000-0003-4066-5253

\section{REFERENCES}

1 Joint Royal College of Physicians Training Board. Speciality training curriculum in respiratory medicine (Ammendments 2014); 2010.

2 Sivakumar P, Kamalanathan M, Collett AS, et al. Thoracic ultrasound experiences among respiratory specialty trainees in the UK. Clin Med 2017;17:408-11.

3 Fallon J, Medford ARL. Endobronchial and transbronchial biopsy experience: a United Kingdom survey. Thorac Cancer 2017;8:291-5.

4 Desai NR, Parikh MS, Lee HJ. Interventional pulmonology: the role of simulation training and competency-based evaluation. Semin Respir Crit Care Med 2018;39:747-54.

5 Corbetta L, Arru LB, Mereu C, et al. Competence and training in interventional pulmonology. Panminerva Med 2019;61:203-31.

6 Ernst A, Wahidi MM, Read CA, et al. Adult bronchoscopy training: current state and suggestions for the future: chest expert panel report. Chest 2015;148:321-32.

7 Dabscheck EJ, Hew M, Irving L, et al. Bronchoscopic training and practice in Australia and New Zealand is inconsistent with published Society guidelines. J Bronchology Interv Pulmonol 2014;21:117-22. 
8 Gilbert CR, Yarmus L, Feller-Kopman D. Educating the next generation of pulmonary fellows in transbronchial needle aspiration. leading the blind to see. Ann Am Thorac Soc 2014;11:828-32.

9 Voduc N, Dudek N, Parker CM, et al. Development and validation of a bronchoscopy competence assessment tool in a clinical setting. Ann Am Thorac Soc 2016;13:495-501.

10 Davoudi M, Colt HG, Osann KE, et al. Endobronchial ultrasound skills and tasks assessment tool: assessing the validity evidence for a test of endobronchial ultrasound-guided transbronchial needle aspiration operator skill. Am J Respir Crit Care Med 2012;186:773-9.

11 Konge L, Larsen KR, Clementsen P, et al. Reliable and valid assessment of clinical bronchoscopy performance. Respiration 2012;83:53-60.

12 Fielding DI, Maldonado F, Murgu S. Achieving competency in bronchoscopy: challenges and opportunities. Respirology 2014;19:472-82.
13 Stather DR, MacEachern P, Chee A, et al. Evaluation of clinical endobronchial ultrasound skills following clinical versus simulation training. Respirology 2012;17:291-9.

14 Siau K, Green JT, Hawkes ND, et al. Impact of the joint Advisory group on gastrointestinal endoscopy (JAG) on endoscopy services in the UK and beyond. Frontline Gastroenterol 2019;10:93-106.

15 Cho AR, Lim I, Na II, et al. Evaluation of adrenal masses in lung cancer patients using F-18 FDG PET/CT. Nucl Med Mol Imaging 2011;45:52-8.

16 Stanton AE, Edey A, Evison M, et al. British thoracic Society training standards for thoracic ultrasound (Tus). BMJ Open Respir Res 2020; 7:e000552.

17 BTS Flexible Bronchoscopy Quality Standards Working Group. Quality standards for diagnostic flexible bronchoscopy in adults. British Thoracic Society 2014 